\title{
Determination of phosphate in water by flow coulometry
}

\author{
A. Manováa ${ }^{\text {E. Beinrohr }}{ }^{\mathrm{b}}$ \\ ${ }^{a}$ Slovak University of Technology, Faculty of Chemical and Food Technology Institute of Analytical Chemistry, \\ Radlinského 9, 81237 Bratislava, Slovakia \\ ${ }^{b}$ Department of Chemistry, Faculty of Natural Sciences, University of SS. Cyril and Methodius in Trnava \\ alena.manova@stuba.sk
}

\begin{abstract}
In this work, the possibility of flow coulometry application as coulometric titration was studied. The method was used to analyze phosphates in wastewater samples. The principle of the determination consisted in the formation of molybdophosphate and its subsequent one-electron electrolytic reduction. The present method is applicable under optimal conditions in the concentration range of $1.5 \times 10^{-6}$ to $5.5 \times 10^{-5} \mathrm{~mol} / \mathrm{dm}^{3}$. Detection limit of the method is $3.42 \times 10^{-7} \mathrm{~mol} / \mathrm{dm}^{3}$. Mineralization step has been proved a problem in total phosphate content determination. If mineralization was not carried out, only inorganic soluble phosphates were determined. It is a new method characterized by its simplicity of instrumentation and handling, which is a prerequisite for its further use in the field of trace analysis.
\end{abstract}

Keywords: coulometry, coulometric titration, phosphates, wastewater samples, porous electrode

\section{Introduction}

Coulometry is based on the measurement of the electrical charge required to affect the electrochemical conversion of a studied substance. Faraday's law expresses the relationship between the amount of the substance and the charge. Coulometric measurements are very often used for quantitative analysis. With complete electrolytic conversion of the studied substance while maintaining the current efficiency of $100 \%$, this method can be used for direct or indirect determination of the substance without any reference materials in the coulometric analysis. The coulometric measurement can be performed for electrolysis at controlled current or potential. For coulometric titration of the sample solution in the porous electrode volume, no separate indicator system is required. If the pore size is approximately equal to the thickness of the diffusion layer, concentration of the analyte during electrolysis is practically the same throughout the electrode volume. In accordance with the Nernst equation, a change in the analyte concentration in the electrode volume is reflected by the change in the electrode potential. When the substance titration is complete, the electrode potential changes abruptly, indicating an equivalent point. In this way, substances which can be electrochemically oxidized or reduced in the aqueous solution or converted into an electrochemically active form can be titrated. Such substances also include phosphates and they, form a complex compound when reacted with ammonium molybdate with the P:Mo ratio of 1:12 (Heslop and Jones, 1985). Thus bound hexavalent molybdenum is electrochemically reduced to pentavalent at different potential than molybdenum not bound to a heteropolyacid salt. Thus, an electrochemical reaction takes place on the electrode:

$$
\mathrm{Mo}^{6+}+\mathrm{e}^{-}=\mathrm{Mo}^{5+}
$$

Phosphate content can be determined by the amount of molybdenum reduced. The high molybdenumphosphorus binding rate ranks this method among very sensitive methods of quantitative analysis of phosphates in water. Phosphorus is mainly present in water in form of various phosphates: inorganic phosphates, polyphosphates, and organically bound phosphorus. Methods available in a conventional laboratory do not enable, the determination of individual groups of compounds as exact distribution cannot be achieved. All groups of phosphorus compounds are determined by their conversion to soluble inorganic orthophosphates which are then determined by absorption spectrophotometry (Nollet and De Gelder, 2000).

The Handbook of Water Analysis provides 29 references to phosphate determination in literature.

The review by Zaporozhets et al. (2019) covers the advantages of phosphorus determination in environmental objects such as saline and fresh water, soil, human serum and urine, food and fertilizers for the period of 2000-2018. Spectrophotometry as well as spectrophotometry combined with liquid or solid-phase extraction, flow-analysis system, electrochemical, luminescent and visual test-system have been considered. Spectrophotometry remains the most multipurpose method (applicable for the analysis of different objects), cost-effective despite 
the rapid progress of electrochemical sensors. Flow-analysis systems are successfully implemented for surface and groundwater analysis as well as for saline water. Complex multicomponent luminescent and voltamperometric systems are used for phosphorus determination in biological matrices, e.g. serum and blood plasma, urine, etc. Test-systems can provide simple and prompt reactive phosphate monitoring without using complex devices. However, the limitation of columns with color band formation include the short range of phosphate concentrations and UV radiation effect on some components of paper-based test-systems.

Snigur et al. (2020) reported fast room temperature cloud point procedure for spectrophotometric determination of phosphate in water samples with linear calibration graph in the phosphate concentrations range of $1.58-63 \mu \mathrm{g} / \mathrm{L}$.

This topic has also been studied by Afkhami and Norooz-Asl (2009) in the work 'Cloud point extraction for the spectrophotometric determination of phosphorus(V) in water samples'. Linearity was obeyed in the range of $1.0-125 \mathrm{ng} / \mathrm{mL}$ of $\mathrm{P}$ and the detection limit of the method was $0.5 \mathrm{ng} / \mathrm{mL}$ of $\mathrm{P}$. Najafi and Hashemi (2020) introduced a new supramolecular solvent from a non-ionic nonylphenol ethoxylate surfactant, and its potential was evaluated for microextraction of orthophosphate before molybdenum blue spectrophotometric determination. Under the optimized conditions, orthophosphate can be determined in the linear range of $0.5-28.0 \mu \mathrm{g} / \mathrm{L}$ $\left(\mathrm{R}^{2}=0.9933\right)$ with the detection limit of $0.1 \mu \mathrm{g} / \mathrm{L}$ and preconcentration factor of 50 .

Katsaounos et al. (2003), in an effort to monitor orthophosphate in natural waters and wastewater in the Ipirous region (Greece), proposed an analytical interference-free determination method for low $\mathrm{mg} / \mathrm{L}$ levels, preparing a derivative which conveniently solubilized in the micelles of a non-ionic surfactant under mild conditions, and using spectrophotometrical measurements at $370 \mathrm{~nm}$ after its uptake with a sulfuric acid-methanol solution. Preconcentration of $10 \mathrm{~mL}$ of the sample volume provided the detection limit of $2.6 \mu \mathrm{M}$.

In the work by Kiso et al. (2002), an alternative phosphate spot test is introduced, where phosphate concentration is measured by the color band length of phosphoantimonylmolybdenum blue formed in a detection tube similar to a gas detection tube. This method has been successfully used for the determination of phosphate concentrations in actual wastewaters, indicating the quantification range of $3-18 \mathrm{mg} / \mathrm{L} \mathrm{PO}_{4}{ }^{3-}$ without dilution prior to the analysis.

The determination of phosphates as dissolved anions using ionic liquid chromatography was studied by Xie et al. (2019). The determination range was $1-500 \mathrm{mg} / \mathrm{L}$ and the detection limit was in the range of $0.17-0.54 \mathrm{mg} / \mathrm{L}$.

Special attention has been paid to preconcentration methods and the chromatographic determination of heteropoly acids in phosphorus determination (Dubovik et al., 2003, Tikhomirova et al., 2002). Detection limit for phosphorus is $(6.7 \times 1.2) \times 10^{-3} \mu \mathrm{g} / \mathrm{mL}$. Calibration curve for phosphorus is linear in the concentration range of $0.02-0.15 \mu \mathrm{g} / \mathrm{mL}$.

Different electrochemical sensing strategies adopted for the determination of phosphate using selective ionophores are discussed in the review 'Determination of inorganic phosphate by electroanalytical methods' (Berchmans et al., 2012). The sensing strategies are classified based on the electrochemical detection techniques used viz. potentiometry, voltammetry, amperometry, unconventional electrochemical methods, etc. Enzymatic sensing of phosphate coupled with electrochemical detection is also included. Various electroanalytical methods available in literature were assessed for their advantages in terms of selectivity, simplicity, miniaturization, adaptability, and suitability for field measurements.

Berchmans et al. (2011) reported an amperometric method for phosphate analysis based on the use of a surface modified glassy carbon electrode. The linear range of detection for phosphate is between 19 and $100 \mathrm{pM}$ with the first electrode configuration. The limit of determination can be extended to a lower range, $0.79-32 \mu \mathrm{M}$, using the second electrode configuration.

In the paper 'Novel reagentless paper-based screenprinted electrochemical sensor to detect phosphate' (Cinti et al., 2016), a novel reagent-less paper-based electrochemical phosphate sensor was prepared using a simple and inexpensive approach. This novel and highly sustainable configuration readily enables the determination of phosphate ions with high reproducibility and long storage stability, achieving the detection limit of $4 \mu \mathrm{M}$ over a wide linear range of up to $300 \mathrm{mM}$.

Initial steps in the development of an autonomous in situ electrochemical sensor for orthophosphate determination in seawater were presented by Jonca et al. (2011). The molybdophosphate complex is detectable by amperometry with an average precision of $2.2 \%$ for the concentration range found in the open ocean and the detection limit of $0.12 \mu \mathrm{M}$. Kahveci et al. (2017) described the development of a novel fluorescent biosensor based on the inhibition of alkaline phosphatise.

On basis of the composite, a novel ratiometric fluorescence probe with good sensitivity and selectivity 
for the detection of phosphate in aqueous solutions was developed (Dai et al., 2015). The limit of detection is $0.06 \mu \mathrm{M}$ and the relative standard deviation for ten replicate detections of $10 \mu \mathrm{M}$ phosphate was $0.6 \%$. Recovery of spiked phosphate in water, human urine, and serum samples ranged from $94.1 \%$ to $103.4 \%$.

Knochen (2020) specified continuous flow analysis (CFA) methods for the determination of orthophosphate indicating the mass concentration range from $0.01 \mathrm{mg} / \mathrm{L}$ to $1.00 \mathrm{mg} / \mathrm{L} \mathrm{P}$, and total phosphorus in the mass concentration range from $0.10 \mathrm{mg} / \mathrm{L}$ to $10.0 \mathrm{mg} / \mathrm{L} \mathrm{P}$.

A novel and automated sequential injection procedure for spectrophotometric determination of orthophosphate without unstable chemical reducing species used in the classical molybdenum blue method was proposed by Mas-Torres et al. (2004). The proposed method is linear up to $20 \mathrm{mg} / \mathrm{L} \mathrm{P}$ and the proposed analyzer features an extremely wide dynamic range of $0.3-800 \mathrm{mg} / \mathrm{L}$ as well as improved tolerance to silicate interference.

A sequential injection system with dual analytical line was developed and applied by Mesquita et al. (2011), who compared two different detection systems: a conventional spectrophotometer with a commercial flow cell, and a multi-reflective flow cell coupled with a photometric detector under the same experimental conditions. The achieved detection limit of $0.007 \mu \mathrm{M} \mathrm{PO}_{4}{ }^{3-}$ is consistent with the requirement of the target water samples; a wide quantification range of $0.024-9.5 \mu \mathrm{M}$ was achieved using both detection systems.

Automation of the molybdenum blue method by sequential injection (SIA) for on-line monitoring of phosphate in natural waters was presented by van Staden and Taljaard (1998). The proposed SIA analyzer is able to monitor phosphate in the range of $0-70 \mathrm{mg} / \mathrm{L}$ with a standard deviation of $0.9 \%$. The detection limit is $0.5 \mathrm{mg} / \mathrm{L} \mathrm{PO}_{4}{ }^{3-}$.

The aim of the paper 'Determination of phosphorus in natural waters: A historical review' (Worsfold et al., 2016) introduced a virtual special issue reviewing the development of analytical approaches to the determination of phosphorus species in natural waters.

Environmentally friendly, simple and sensitive isotachophoretic method for the identification and quantification of orthophosphates, pyrophosphates, tripolyphosphates in various samples was developed (Jastrzebska, 2011). This system is characterized by its linearity $\left(\mathrm{R}^{2}=0.999\right.$ for all ions), accuracy (recoveries ranging from 97 to $98 \%$ for pyroP and 95 to $97 \%$ for tripolyP), detection: 0.64 (pyroP) and $0.27 \mathrm{mg} / \mathrm{L} \mathrm{P}$ (tripolyP) and quantification: 2.12 (pyroP) and $0.91 \mathrm{mg} / \mathrm{L} \mathrm{P}$
(tripolyP) limits, as well as by intra-assay of relative step height RSH (1.27-10.73\%) and inter-assay of RSH (3.95-11.17\%).

\section{Experimental}

Chemicals of defined purity and deionized water, purified with a NANOpure instrument, boiled and cooled before the measurement, were used throughout the analyses. For calibration, a $0.1 \mathrm{~mol} / \mathrm{dm}^{3} \mathrm{HCl}$ solution was used as the electrolyte. A solution of $0.0001 \mathrm{~mol} / \mathrm{dm}^{3}$ of $\mathrm{K}_{4}\left[\mathrm{Fe}(\mathrm{CN})_{6}\right] \cdot 3 \mathrm{H}_{2} \mathrm{O}$ in $0.1 \mathrm{~mol} / \mathrm{dm}^{3}$ of $\mathrm{HCl}$ was used to calibrate the electrode. Electrolyte for the measurement of phosphates with the following composition: $0.00284 \mathrm{~mol} / \mathrm{dm}^{3}$ of $\mathrm{Mo}$ and $0.1 \mathrm{~mol} / \mathrm{dm}^{3}$ of $\mathrm{H}_{2} \mathrm{SO}_{4} \cdot \mathrm{NaH}_{2} \mathrm{PO}_{4} \cdot 2 \mathrm{H}_{2} \mathrm{O}$ dried at $105{ }^{\circ} \mathrm{C}$ for two hours, was used to prepare $1.0 \times 10^{-5} \mathrm{~mol} / \mathrm{dm}^{3}$ of phosphate in electrolyte solution for model samples. Interferences of substances such as humic acid and other inorganic ions were monitored. An ECA Elow $^{\text {flodel GLP }}$ 150 (Istran, Ltd., Bratislava, Slovakia; internet address: www.istran.sk) flow analyzer for calibration-less analysis of trace concentrations of the analyte was used. An integrated three-electrode electrochemical cell was coupled with an easily replaceable powdered glass working electrode showing the most advantageous properties in terms of use. The procedure consisted of flow analyzer preparation for the measurement, replacement of the working electrode if necessary, removal of air bubbles, and determation of the flow rate. The measurement procedure consisted of setting the working parameters, determination of the effective electrode volume, measurement, and final integration of the dissolution peak to obtain the measured analyte concentration in the sample. Some matrices such as: high solids samples, dissolved gases, samples containing strong oxidizing agents, sulfur compounds, and organic substances affect the yield, which results in a systematic error, when these possible interfering disturbances have to be removed. Samples were taken in three wastewater treatment plants in the district of Dunajska Streda by employees of Zapadoslovenska vodarenska spolocnost a.s. Dunajska Streda into PE containers and subsequently treated.

\section{Results and Discussion}

\section{Electrode calibration}

Several substances were used to calibrate the effective electrode volume, of which $\mathrm{K}_{4}\left[\mathrm{Fe}(\mathrm{CN})_{6}\right] \cdot 3 \mathrm{H}_{2} \mathrm{O}$ was the most successful. The effective electrode 
volume depends on the electrode dimensions but mainly on the oxidation current. As the oxidation current increases, the effective electrode volume decreases due to uneven loss of analyte in the electrode. At the electrode surface, electrolysis proceeds faster than in the center of the electrode, where unoxidized analyte remains at higher oxidation current. The peak height decreased, and the peak position shifted to higher values. The effective electrode volume was about $20 \times 10^{-6} \mathrm{dm}^{3}$.

\section{Optimization of measurement parameters}

Working parameters of the measurement were used to optimize the reduction current, filling potential, sample volume and electrolyte composition. The effect of temperature on phosphate determination was also studied using currents ranging from $-0.1 \mathrm{~mA}$ to $-0.8 \mathrm{~mA}$ to reduce the model sample of phosphate with the concentration of $1 \times 10^{-5} \mathrm{~mol} / \mathrm{dm}^{3}$. Reducing current of $-0.2 \mathrm{~mA}$ was chosen as optimal because at this current the measured concentration corresponded to the actual value. Therefore, when replacing the electrode, effective electrode volume was calibrated at the oxidation current of $0.2 \mathrm{~mA}$. As the absolute current increased, the signal height decreased, and the peak maximum position shifted to more negative values. At the optimum filling potential, the electrode should be completely filled with the sample solution and no electrode reactions should occur. The measurement was performed with a model sample ranging from $-300 \mathrm{mV}$ to $800 \mathrm{mV}$. The measured phosphate concentration approached the true value at the filling potential of $0 \mathrm{mV}$.

The sample volume was optimized based on the assumption that analyte adsorption to the electrode also occurs during electrode loading. This as- sumption can be confirmed by the increase of the measured concentration with the increasing sample volume. However, the measurement results did not confirm this assumption.

Electrolyte optimization was done by varying the concentrations of $\mathrm{H}_{2} \mathrm{SO}_{4}$ and molybdenum, thus changing the ratio of hexavalent molybdenum to phosphate anions. The measured value corresponded to the actual molybdenum/phosphate ratio of 284:1, which corresponds to the of $\mathrm{H}_{2} \mathrm{SO}_{4}$ concentration of $0.1 \mathrm{~mol} / \mathrm{dm}^{3}$.

Chronopotentiometric recording of phosphate measurements is presented in Fig 1.

\section{Interference effects}

Interferences were observed in a model phosphate sample solution with given additions of interfering inorganic ions and humic acid. $\mathrm{Fe}^{2+}$ ions caused positive measurement error, $\mathrm{Ca}^{2+}$ and $\mathrm{NO}^{3-}$ ions influenced the determination to a minor extent, $\mathrm{Cl}^{-}, \mathrm{Na}^{+}, \mathrm{Mn}^{2+}, \mathrm{Mg}^{2+}$ ions, and especially $\mathrm{Fe}^{3+}$ ions at higher concentrations caused negative error of determination. Measurements of humic acid interference showed that phosphates concentrations above $5.0 \times 10^{-3} \mathrm{~g} / \mathrm{dm}^{3}$ cannot be determined.

\section{Metrological parameters}

Metrological parameters such as results accuracy, measurement repeatability, detection limit and working range were monitored. Results accuracy for concentrations below $1.0 \times 10^{-6} \mathrm{~mol} / \mathrm{dm}^{3}$ was $13 \%$ and more, from $1.5 \times 10^{-6} \mathrm{~mol} / \mathrm{dm}^{3}$ to $5.5 \times 10^{-5} \mathrm{~mol} / \mathrm{dm}^{3}$ it was $2 \%$ and from $5.5 \times 10^{-5} \mathrm{~mol} / \mathrm{dm}^{3}$ to $8.0 \times 10^{-5} \mathrm{~mol} / \mathrm{dm}^{3}$ it was from $7 \%$ to $20 \%$. When investigating measurement repeatability, the average measured concentration of phosphate in the model sample over ten

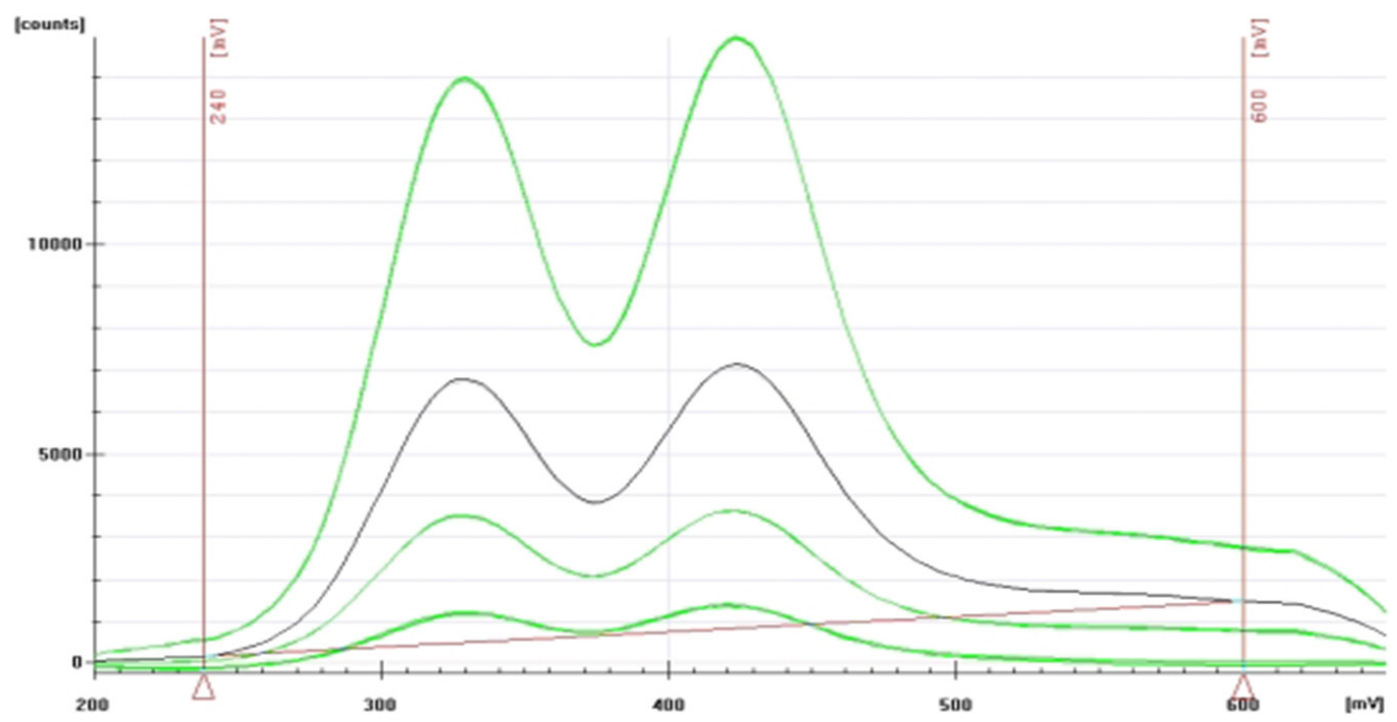

Fig. 1. Chronopotentiometric recording of phosphate. 
days was $1.003 \times 10^{-5} \mathrm{~mol} / \mathrm{dm}^{3}$ with a relative standard deviation of $0.60 \%$. The detection limit of the method is $3.42 \times 10^{-7} \mathrm{~mol} / \mathrm{dm}^{3}$. The presented method is applicable under optimal conditions in the concentration range of $1.5 \times 10^{-6}$ to $5.5 \times 10^{-5} \mathrm{~mol} / \mathrm{dm}^{3}$ (Slana, 2001).

\section{Analysis of real samples}

Wastewater samples were taken before and after the treatment in Slovak cities Kuty, Samorin and Gabcikovo as 8-hour cast samples. Activated charcoal was added to the collected fractions to remove colloids and other interferents. The samples were then filtered through filter paper and preserved by the addition of $\mathrm{CHCl}_{3}$ to prevent biological processes. The measured phosphate concentrations in real wastewater samples from given sites before (1) and after (2) the treatment in a wastewater treatment plant are given in Table 1 which provides the confidence interval of phosphate concentrations determined without and with the standard addition by the flow coulometric method and the phosphate concentrations determined spectrophotometrically after mineralization according to the standard norm (STN EN ISO 6878 (757465)).

Phosphate concentrations measurements by flow coulometry (Methodological guidelines 1982) were performed with non-mineralized samples and therefore only the content of dissolved inorganic phosphates is probably obtained. For the mineralized sample from location Kuty taken prior to purification, a poorly integrated high peak with the maximum shifted by about $40 \mathrm{mV}$ to more positive values was obtained. At the indicated integration, the phosphate concentration was $4.60 \mathrm{mg} / \mathrm{dm}^{3}$ and no peak in the potential range typical for reduction of molybdophosphate was observed. This indicates a likely disturbance of the mineralization background and therefore, mineralization of the blank was performed. The result of this measurement showed a peak similar to that of the sample, of course, approximately ten times smaller. After adding the standard addition to the blank mineralization experiment, a peak similar to that of a real sample, with a significantly shifted the maximum and high signal, was obtained. Another standard addition caused that the peak height increased only to a small and apparently inadequate extent. Nonconformity of the results measured by flow coulometry and spectrophotometry and the procedure of wastewater samples mineralization will be the subject of further study.

\section{Conclusion}

The aim of the presented work was to study the application of flow coulometry as coulometric titration. The method was used to analyze phosphates in wastewater samples. The determination principle consisted in the formation of molybdophosphate and its subsequent one-electron reduction. The presented method is applicable under optimal conditions in the concentration range of $1.5 \times 10^{-6}$ to $5.5 \times 10^{-5} \mathrm{~mol} / \mathrm{dm}^{3}$. The detection limit of the method is $3.42 \times 10^{-7} \mathrm{~mol} / \mathrm{dm}^{3}$. The mineralization step in total phosphate content determination was problematic. If the mineralization was not carried out, only inorganic soluble phosphates were determined. It is a new method characterized by its simplicity of instrumentation and handling, which is a precondition of its further use in trace analysis. As this is an absolute method it ranks among reliable and independent methods.

\section{Acknowledgement}

This work was supported by the Slovak Grant Agency (VEGA No 1/0489/16).

Tab. 1. Measured concentrations of phosphate in real samples.

\begin{tabular}{lccc}
\hline Location & $\begin{array}{c}\text { Concentration* } \\
\text { without standard addition } \\
{\left[\mathrm{mg} / \mathrm{dm}^{3}\right]}\end{array}$ & $\begin{array}{c}\text { Concentration** } \\
\text { with standard addition } \\
{\left[\mathrm{mg} / \mathrm{dm}^{3}\right]}\end{array}$ & $\begin{array}{c}\text { Concentration*** } \\
{\left[\mathrm{mg}^{*} / \mathrm{dm}^{3}\right]}\end{array}$ \\
\hline Kuty 1 & $1.64 \pm 0.04$ & $2.91 \pm 0.12$ & 2.67 \\
Kuty 2 & $0.53 \pm 0.02$ & $1.74 \pm 0.03$ & $3.69 \pm 0.11$ \\
Samorin 1 & $1.88 \pm 0.09$ & $1.77 \pm 0.02$ & 5.11 \\
Samorin 2 & $0.53 \pm 0.02$ & $3,15 \pm 0,18$ & 5.54 \\
Gabcikovo 1 & $1,91 \pm 0,07$ & $2,59 \pm 0,08$ & 5,86 \\
Gabcikovo 2 & $1,43 \pm 0,05$ & & 5,48 \\
\hline
\end{tabular}

\footnotetext{
*measured by flow coulometry

**measured by flow coulometry with standard addition of $1.24 \mathrm{mg} / \mathrm{dm}^{3}$

***measured spectrophotometrically
} 


\section{References}

Afkhami A, Norooz-Asl R (2009) Journal of Hazardous Materials 167: 752-755.

Berchmans S, Issa TB, Singh P (2012) Analytica Chimica Acta 729: 7-20.

Berchmans S, Karthikeyan R, Gupta S, Poinern GEJ, Issa TB, Singh P (2011) Sensors and Actuators B-Chemical 160: 1224-1231.

Cinti S, Talarico D, Palleschi G, Moscone D, Arduini F (2016) Analytica Chimica Acta 919: 78-84.

Determination of trace elements by flow coulometry (1982) Methodological guidelines compiled according to ISO 78/2. ISTRAN, Ltd., Bratislava.

Dai C, Yang CX, Yan XP (2015) Analytical Chemistry 87: $11455-11459$.

Dubovik DB, Tikhomirova TI, Ivanov AV, Nesterenko PN, Shpigun OA (2003) Journal of Analytical Chemistry 58: 802-819.

Heslop RB, Jones K (1985) Inorganic Chemistry. SNTL, Prague.

Chemical and physical analysis of wastewater (2004) STN EN ISO 6878 (757465).

Jastrzebska A (2011) Journal of Food Composition and Analysis 24: 1049-1056.

Jonca J, Fernandez VL, Thouron D, Paulmier A, Graco M, Garcon V (2011) Talanta 87: 161-167.

Kahveci Z, Martinez-Tome MJ, Mallavia R, Mateo, CR (2017) ACS Applied Materials \& Interfaces 9: 136-144.

Katsaounos CZ, Giokas DL, Vlessidis AG, Paleologos EK, Karayannis MI (2003) Science of the Total Environment 305: 157-167.
Kiso Y, Kuzawa K, Saito Y, Yamada T, Nagai M, Jung YJ, Min KS (2002) Analytical and Bioanalytical Chemistry 374: 1212-1217.

Knochen M, Carlos Rodriguez-Silva J, Silva-Silva J (2020) Talanta 209.

Mas-Torres F, Estela JM, Miro M, Cladera A, Cerda V (2004) Analytica Chimica Acta 510: 61-68.

Mesquita RBR, Ferreira MTSOB, Toth IV, Bordalo AA, McKelvie ID, Rangel AOSS (2011) Analytica Chimica Acta 701: 15-22.

Najafi A, Hashemi M (2020) Journal of Molecular Liquids 297:

Nollet LML, De Gelder LSP (2000) Handbook of Water Analysis. CRC press, New York.

Slana I (2001) Diploma Thesis, Faculty of Chemical and Food Technology Slovak University of Technology in Bratislava.

Snigur D, Chebotarev A, Duboviy V, Bulat K (2020) Analytical Biochemistry 597.

van Staden JF, Taljaard RE (1998) Microchimica Acta 128: 223-228.

Tikhomirova TI, Krokhin OV, Dubovik DB, Ivanov AV, Shpigun OA (2002) Journal of Analytical Chemistry 57: 18-23.

Worsfold P, McKelvie I, Monbet P (2016) Analytica Chimica Acta 918: 8-20.

Xie WJ, Wang XL, Li YS, Xu DH, Zhong YJ, Yang JX (2019) Chromatografia 82: 1687-1695.

Zaporozhets OA, Zinko LS, Sumarokova GS (2019) Methods and Objects of Chemical Analysis 14: $175-191$. 